\title{
Addition of sodium metabisulphite to left atrial catheter infusates as a means of preventing bacterial colonisation of the catheter tip
}

\author{
R FREEMAN, MP HOLDEN, R LYON, N HJERSING \\ From the Departments of Microbiology, Cardiothoracic Surgery, and Pharmacy, Freeman Hospital, \\ Newcastle upon Tyne
}

\begin{abstract}
Sodium metabisulphite (SMBS) was added at a concentration of $0.05 \%$ to the dextroseheparin solution used to flush left atrial catheters in one group of open-heart surgery patients. Two other groups of patients had left atrial catheters flushed with dextrose-heparin alone. Comparison of the isolation rate of organisms from the tips of the catheters in the three groups showed that the addition of SMBS significantly reduced bacterial contamination in the lines (two isolations from 36 catheters with SMBS added, compared with 13 from 56 and 15 from 65 in the other groups-that is, $5.55 \%$ compared with $23.2 \%$ and $23.1 \%$ ). The protective effect of the SMBS was particularly evident in the first 48 hours after catheter insertion. No haematological or biochemical insult was found.
\end{abstract}

In an earlier report from this unit it was found that the use of inotropic agents via the right atrial catheter resulted in apparent protection against bacterial colonisation. ${ }^{1}$ This protective effect was traced to the sodium metabisulphite (SMBS) incorporated into the inotropic agent solution as an anti-oxidant. It is well known that SMBS is an antiseptic agent, ${ }^{2}$ and the substance is widely used in food preservation. Thus, open-heart surgical patients had been receiving a mild intravenous antiseptic for many years, without apparent adverse effects. It was thought desirable, therefore, to assess the effects of adding SMBS in similar concentration to other catheters in these patients. In particular, the effects on bacterial colonisation of the left atrial catheter tip were to be assessed since this catheter overlies the newly implanted valve in many cases.

\section{Methods}

All adult patients undergoing open-heart surgery and in whom left atrial catheters were inserted were included, and were consecutive cases. The postoperative care which such patients receive is reasonably standardised and common to the patients of all three surgeons involved in this study. The catheters

Address for reprint requests: Dr R Freeman, Department of Microbiology, Freeman Hospital, Freeman Road, High Heaton, Newcastle upon Tyne NE7 7DN. are inserted in the operating theatre and are flushed on a continuous basis thereafter with a solution of $5 \%$ dextrose, to which heparin is added at a concentration of $2 \mathrm{u} / \mathrm{ml}$. This solution is supplied from a $500 \mathrm{ml} \mathrm{bag}$, and is running at a rate of $2 \mathrm{ml} /$ hour. A monitor prevents the flow rate exceeding $8 \mathrm{ml} /$ hour. The reservoir bag is changed every 24 hours.

Sodium metabisulphite was prepared in the pharmacy as a sterile $5 \%$ solution, stored under nitrogen, and dispensed into $5 \mathrm{ml}$ aliquots. The addition of one aliquot to a $500 \mathrm{ml}$ bag of dextrose (together with the heparin) thus produced a solution of $0.05 \%$ SMBS in dextrose-heparin. This solution was used to flush left atrial catheters in the study group (see below) in an identical manner to the control groups, the bags being changed at the usual interval.

One hundred and fifty-seven patients were in cluded, 36 being patients of surgeon A, 56 of surgeon $B$, and 65 of surgeon C. Left atrial catheters of the patients under care of surgeon $A$ were flushed with dextrose-heparin + SMBS, the remainder with the standard dextrose-heparin solution.

At removal of the catheter, the severed tip was sent for culture as previously described. It is important to note that the cultural technique used was a recent improvement of an earlier technique, ${ }^{3}$ and included prolonged incubation, and neutralisation of the prophylactic antibiotic (flucloxacillin) being given to the patient. 
Table 1 Isolation rates of organisms from left atrial catheter tips in the three groups of patients

\begin{tabular}{|c|c|c|c|c|c|c|}
\hline \multirow[t]{2}{*}{ Group } & \multirow{2}{*}{$\begin{array}{l}\text { Number in } \\
\text { group }\end{array}$} & \multirow[t]{2}{*}{ Isolations } & \multicolumn{4}{|c|}{ Nature of organisms isolated } \\
\hline & & & CNS & $D I P H$ & COLIF & STREP \\
\hline A (SMBS) & 36 & $2(5.55 \%)$ & 1 & 1 & - & - \\
\hline B (no SMBS) & 56 & $13(23 \cdot 2 \%)$ & 9 & 3 & - & 1 \\
\hline$C$ (no SMBS) & 65 & $15(23 \cdot 1 \%)$ & 11 & 3 & 1 & - \\
\hline$B+C$ & 21 & $28(23 \cdot 1 \%)$ & 20 & 6 & 1 & 1 \\
\hline
\end{tabular}

Key: CNS = coagulase-negative staphylococci DIPH = diphtheroids; COLIF = coliforms; STREP $=$ streptococci.

Statistical note: comparing A with $\mathrm{B}, \mathrm{p}=<0.1>0.05$; A with $\mathrm{C}, \mathrm{p}=<0.05$; B with $\mathrm{C}, \mathrm{p}=>0.8$; A with $\mathrm{B}-\mathrm{C}, \mathrm{p}=<0.05$.

Finally, the postoperative routine biochemical and haematological parameters of each patient receiving the SMBS solution were scrutinised to exclude any possible adverse effects of the SMBS administration.

\section{Results and discussion}

It can be seen in table 1 that there is a substantial reduction in the isolation rate of organisms in the catheter tip cultures in those patients given dextroseheparin containing SMBS. When group A is compared with group $\mathrm{C}$ or to the control groups combined $(B+C)$ the differences are unlikely to be due to chance. Comparing $\mathrm{A}$ with $\mathrm{B}$ gives a result bordering on significance at the $5 \%$ level. This impression is strengthened by the lack of any significant difference between the two control groups. The isolation rate found in the two control groups is of the order previously obtained from left atrial catheter tip culture when the same improved cultural technique was applied. ${ }^{3}$

The evidence that SMBS exerts a genuine protection against bacterial colonisation of the catheter tip is further strengthened by analysing the results according to the time in situ of each catheter. Thus, the only two isolations made from the SMBS treated group were obtained on days 3 and 6 (table 2). From previous data ${ }^{4}$ it is likely that the risk of colonisation increases substantially with time, and it may be that the concentration of SMBS selected for this initial trial is capable of protecting against the challenge of bacterial colonisation experienced in the first few days in situ, but that repeated and increasing bacterial contamination will eventually overcome the antiseptic. This last point may reflect our unpublished laboratory observations, in which SMBS at $0.05 \%$ inhibited $10^{3}$ staphylococci $/ \mathrm{ml}$ but not $10^{5} \mathrm{staphylococci} / \mathrm{ml}$. If the results presented in table 2 are restricted to the first two days in situ (a period which includes $91 \%$ of the catheters studied, and which would embrace almost all "routine" admissions to the Intensive Care Unit) it can be seen that bacterial colonisation is eliminated from the SMBS-treated patients, compared with an isolation rate of $22.6 \%$ and $22.1 \%$ for the controls.

It is important to examine the limitations of this study. Firstly, although comparative it is not truly random. It was thought that this study would be useful as a pilot trial, and that it should be analysed when it appeared that some discernible effect or lack of effect resulted. This modest objective has now been achieved with a significant difference in favour of the SMBS-treated group. Secondly, the concentration of SMBS used $(0.05 \%)$ is lower than that used in inotropic solutions $(0 \cdot 1 \%)$. This was selected on the basis that many of these patients would also be receiving SMBS as part of inotropic therapy. Thus, any one patient might receive SMBS from two sources and, therefore, the total daily intake of SMBS needed to be calculated. The World Health Organisation has suggested that the daily intake of bisulphite should not exceed $700 \mu \mathrm{g} / \mathrm{kg} / \mathrm{day}$, expressed as equivalents of $\mathrm{SO}_{2} .{ }^{2}$ Calculation reveals that $0 \cdot 1 \%$ SMBS given in the left atrial flush would introduce $480 \mu \mathrm{g} / \mathrm{kg} /$ day and thus would leave little room for a second route, especially if inotropic therapy was intensive. It is, however, clear that the WHO figure is only a suggestion and not derived from direct toxicity studies, and it remains possible that a higher concentration might be used. No biochemical or haematological insult could be found in this study.

A final, very important, limitation is that SMBS is a reducing agent and cannot, therefore, be added to complex intravenous solutions. Thus, it is likely that it will adversely react with proteins and should not

Table 2 Isolations of organisms from left atrial catheter tips related to the time in situ of each catheter

\begin{tabular}{|c|c|c|c|c|c|c|c|c|c|}
\hline \multirow[t]{2}{*}{ Group } & \multirow[t]{2}{*}{ Number } & \multicolumn{8}{|c|}{ Number of catheters removed on each day (isolations in brackets) } \\
\hline & & Day 1 & Day 2 & Day 3 & Day 4 & Day 5 & Day 6 & Day 7 & Day 8 \\
\hline $\begin{array}{l}\text { A } \\
\text { B } \\
\text { C }\end{array}$ & $\begin{array}{l}36 \\
56 \\
65\end{array}$ & $\begin{array}{l}24 \\
52(11) \\
52(11)\end{array}$ & $\begin{array}{l}7 \\
1(1) \\
7(2)\end{array}$ & $\begin{array}{l}3(1) \\
1(1) \\
4(1)\end{array}$ & $\begin{array}{l}0 \\
1 \\
2(1)\end{array}$ & $\begin{array}{l}1 \\
0 \\
0\end{array}$ & $\begin{array}{l}1(1) \\
1 \\
0\end{array}$ & $\begin{array}{l}0 \\
0 \\
0\end{array}$ & $\begin{array}{l}0 \\
0 \\
0\end{array}$ \\
\hline
\end{tabular}


for that reason be added, for instance, to parenteral nutrition therapy; fortunately, the left atrial catheters and other pressure-monitoring lines used after open-heart surgery are unaffected by these limitations and are thus suitable. Sodium metabisulphite provides a simple method of minimising bacterial colonisation without affecting the essential purpose of the catheter, that is monitoring pressures. Previous experience has led us to reject end-line filters for these lines since unacceptable damping of the pressure trace has occurred. Sodium metabisulphite has not been used in femoral artery lines because of the possibility of initiating spasm of the artery.

In conclusion, therefore, the addition of $0.05 \%$ SMBS to the flush solution for left atrial catheters has resulted in a marked reduction in the rate of bacterial colonisation of the catheter tips. No adverse effects were noted. It remains possible that the strength of SMBS can be increased to further good effect and a larger scale trial seems justified. If these preliminary results are confirmed it may be possible to eliminate bacterial colonisation of left and right atrial catheter tips after open-heart surgery.
It will then be possible to assess the importance of this bacterial reservoir in the genesis of early prosthetic valve endocarditis.

We are indebted to $\mathrm{Mr} \mathrm{CJ}$ Hilton and Mr A HedleyBrown for permission to study their patients and to the nursing staff of Ward 26 (Intensive Therapy Unit), Freeman Hospital, without whose help this project would not have been possible.

\section{References}

${ }^{1}$ Freeman R, Hjersing N, Burridge A. Catheter tip cultures on open-heart surgery patients: association with site of catheter and age of patients. Thorax 1981;36:355-9.

${ }^{2}$ Martindale. The Extra Pharmacopoea. Twenty-seventh edition. London: The Pharmaceutical Press, 1979: 1284-5.

${ }^{3}$ Freeman $\mathrm{R}$, Hjersing $\mathrm{N}$. An improved technique for culture of catheter tips from open-heart surgery patients. Thorax 1982;37:145-6.

- Freeman R, King B. Analysis of results of catheter tip cultures in open-heart surgery patients. Thorax 1975;30: 26-30. 